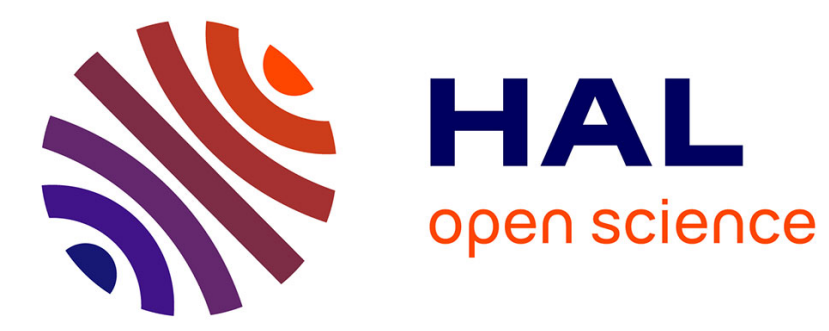

\title{
Te homogeneous precipitation in Ge dislocation loop vicinity
}

J Perrin Toinin, A. Portavoce, M. Texier, M. Bertoglio, K. Hoummada

\section{To cite this version:}

J Perrin Toinin, A. Portavoce, M. Texier, M. Bertoglio, K. Hoummada. Te homogeneous precipitation in Ge dislocation loop vicinity. Applied Physics Letters, 2016, 108. hal-02111623

\section{HAL Id: hal-02111623 \\ https://hal.science/hal-02111623}

Submitted on 26 Apr 2019

HAL is a multi-disciplinary open access archive for the deposit and dissemination of scientific research documents, whether they are published or not. The documents may come from teaching and research institutions in France or abroad, or from public or private research centers.
L'archive ouverte pluridisciplinaire HAL, est destinée au dépôt et à la diffusion de documents scientifiques de niveau recherche, publiés ou non, émanant des établissements d'enseignement et de recherche français ou étrangers, des laboratoires publics ou privés. 


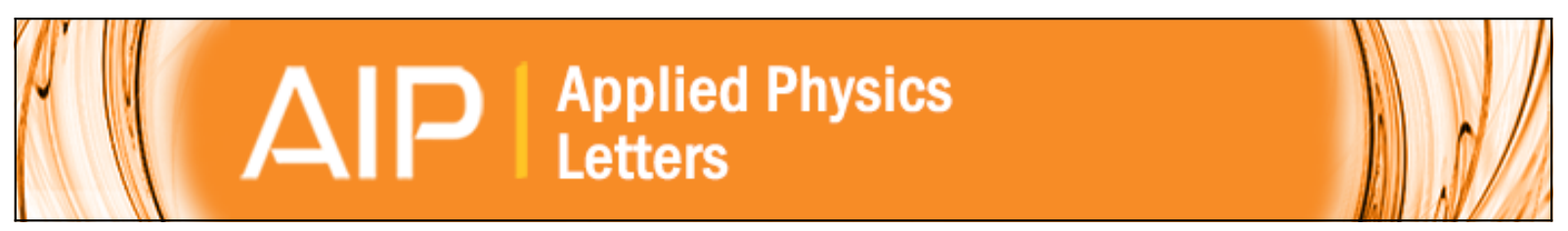

\section{Te homogeneous precipitation in Ge dislocation loop vicinity}

J. Perrin Toinin, A. Portavoce, M. Texier, M. Bertoglio, and K. Hoummada

Citation: Applied Physics Letters 108, 232103 (2016); doi: 10.1063/1.4953627

View online: http://dx.doi.org/10.1063/1.4953627

View Table of Contents: http://scitation.aip.org/content/aip/journal/apl/108/23?ver=pdfcov

Published by the AIP Publishing

\section{Articles you may be interested in}

Evidences of an intermediate rodlike defect during the transformation of $\{113\}$ defects into dislocation loops Appl. Phys. Lett. 89, 161904 (2006); 10.1063/1.2361178

Enhancement effect of germanium on oxygen precipitation in Czochralski silicon

J. Appl. Phys. 99, 073509 (2006); 10.1063/1.2188130

Effect of implantation temperature on dislocation loop formation and origin of $1.55-\mu \mathrm{m}$ photoluminescence from ion-beam-synthesized FeSi 2 precipitates in silicon

Appl. Phys. Lett. 83, 42 (2003); 10.1063/1.1590434

Effects of end-of-range dislocation loops on transient enhanced diffusion of indium implanted in silicon J. Appl. Phys. 88, 4980 (2000); 10.1063/1.1314304

Size-distribution and annealing behavior of end-of-range dislocation loops in silicon-implanted silicon J. Appl. Phys. 81, 78 (1997); 10.1063/1.364099

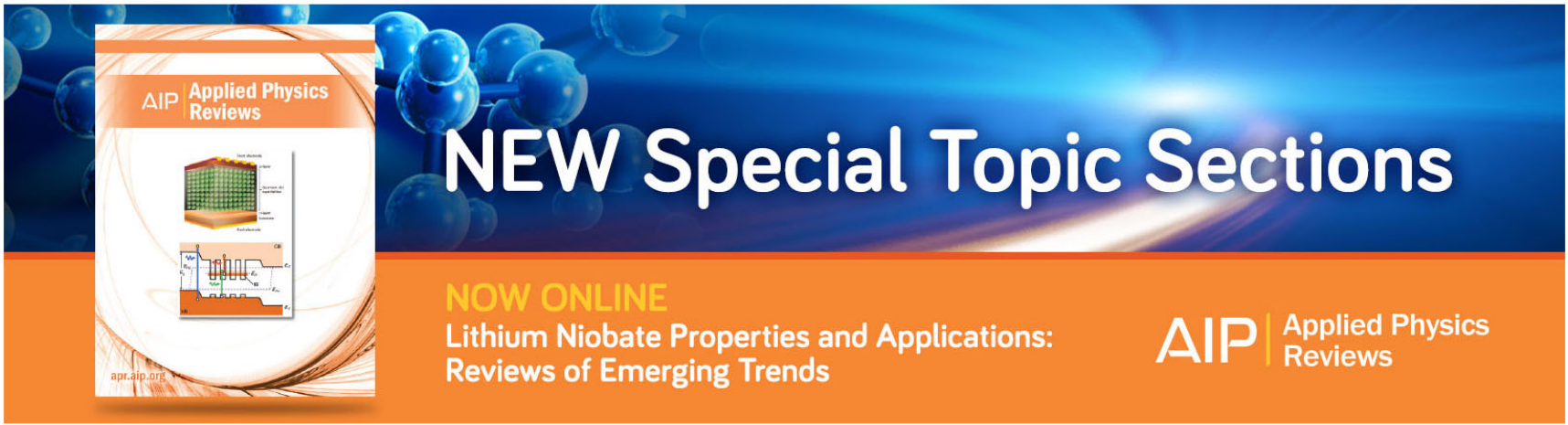




\title{
Te homogeneous precipitation in Ge dislocation loop vicinity
}

\author{
J. Perrin Toinin, A. Portavoce, ${ }^{\text {a) }}$ M. Texier, M. Bertoglio, and K. Hoummada \\ IM2NP, CNRS/Aix-Marseille University, Faculté des Sciences de Saint-Jérôme case 142, 13397 Marseille, \\ France
}

(Received 21 April 2016; accepted 28 May 2016; published online 9 June 2016)

\begin{abstract}
High resolution microscopies were used to study the interactions of Te atoms with Ge dislocation loops, after a standard $n$-type doping process in $\mathrm{Ge}$. Te atoms neither segregate nor precipitate on dislocation loops, but form Te-Ge clusters at the same depth as dislocation loops, in contradiction with usual dopant behavior and thermodynamic expectations. Atomistic kinetic Monte Carlo simulations show that $\mathrm{Te}$ atoms are repulsed from dislocation loops due to elastic interactions, promoting homogeneous Te-Ge nucleation between dislocation loops. This phenomenon is enhanced by coulombic interactions between activated $\mathrm{Te}^{2+}$ or $\mathrm{Te}^{1+}$ ions. Published by AIP Publishing.

[http://dx.doi.org/10.1063/1.4953627]
\end{abstract}

Carrier mobility is faster in $\mathrm{Ge}$ than in $\mathrm{Si}$, and Ge allows lower thermal budget processes to be used compared to Si. Because of Ge compatibility with the current Si-based complementary metal oxide semiconductor (CMOS) technology, and because of the successful development of high-k dielectrics in last generation microelectronic devices, the development of a Ge-based CMOS technology is seriously investigated. ${ }^{1-10}$ However, Ge doping is one of the main difficulties preventing Ge CMOS technology to arise. ${ }^{1,11-17}$ In particular, usual $n$-type Si dopants (such as As and P) exhibit a larger diffusivity and a lower solubility in Ge, ${ }^{1,11-14,17}$ preventing the production of Ge devices as small as current $\mathrm{Si}$ devices (lateral size $<20 \mathrm{~nm}$ ). Thus, advanced doping processes are studied in order to get high doping levels and shallow $p$ - $n$ junctions in $\mathrm{Ge}$, using current single acceptor/donor Si dopants from the columns III and V of the periodic table. ${ }^{11,12,18-22}$ However, the doping potential of several dopants using the current doping technique (dopant implantation followed by rapid thermal annealing) was still poorly investigated. For example, the Te solubility is expected to be low in Ge but not too much different from that of $\mathrm{As}, \mathrm{P}$, and $\mathrm{Sb}$ according to phase diagrams. ${ }^{23}$ However, Te implantation in Ge was not yet reported in the literature, despite that $\mathrm{Te}$ atoms can act as double donors (column VI) in Ge. Heavydopant implantation leads to the formation of dislocation loops (DLs) after dopant activation thermal annealing. ${ }^{24-27}$ These DLs can interact with the implanted dopants, deteriorating the electrical properties of the doped region (transistor source and drain). ${ }^{28}$ Interstitial metals such as $\mathrm{Ni}^{29}$ and substitutional dopants such as $\mathrm{B}$, As, and $\mathrm{P}^{30-32}$ were shown to segregate on Si DLs forming atmospheres located at the edges of DLs. Furthermore, DLs are expected to act as heterogeneous nucleation centres for dopant clusters. ${ }^{33,34}$ In particular, segregation is expected to precede cluster nucleation. $^{33-35}$

In this work, Te atom interaction with Ge DLs was studied after typical $n$-type Ge doping process. Contrasting with dopant behaviours reported so far in the literature, Te atoms

\footnotetext{
${ }^{\text {a) }}$ Author to whom correspondence should be addressed. Electronic mail: alain.portavoce@im2np.fr
}

are shown to not segregate on DLs, and contrasting with general expectations, Te-Ge clusters are shown to nucleate in Ge following homogeneous nucleation, far from DLs but at the same depth. Kinetic Monte Carlo (KMC) simulations show that Te atoms are repulsed from the DLs due to elastic interactions, supporting Te-Ge homogeneous precipitation away from DLs. In addition, coulombic interactions are shown to promote homogeneous GeTe precipitation and to prevent atom segregation to DLs.

$3.1 \times 10^{15} \mathrm{Te}$ at. $\mathrm{cm}^{-2}$ were implanted in an $\mathrm{Ge}(001)$ substrate with a $\mathrm{Te}^{+}$ion beam energy of $180 \mathrm{keV}$. The sample was annealed at $T=650^{\circ} \mathrm{C}$ for $1 \mathrm{~h}$ after implantation, and was characterized by high-resolution transmission electron microscopy (HR-TEM), high-angle annular dark-field scanning transmission electron microscopy (HAADFSTEM), and laser-assisted atom probe tomography (APT). HR-TEM and HAADF-STEM analyses were performed using an FEI Titan 80-300 Cs-corrected microscope operating at $300 \mathrm{kV}$ and equipped with a Gatan Model Ultra Scan 1000P charged-coupling device (CCD) camera and a Gatan Model 806 annular HAADF-STEM detector. STEM images were acquired using a camera length of $195 \mathrm{~mm}$ (collecting angle between 29.77 and $182.08 \mathrm{mrad}$ ). APT analyses were performed using a LEAP $3000 \times \mathrm{HR}$ microscope in the pulsed laser mode. The analyses were carried out at $20 \mathrm{~K}$, with a laser pulse frequency of $100 \mathrm{kHz}$, using a laser power of $0.07 \mathrm{~nJ}$, corresponding to $\mathrm{I}_{\mathrm{Ge}}{ }^{2+} / \mathrm{I}_{\mathrm{Ge}}{ }^{1+}=10$.

Two types of defects located at the same depth were detected after sample annealing: (i) hexagonal DLs located in $\{111\}$ planes, and (ii) Te-Ge clusters. Fig. 1(a) presents an HR-TEM cross-section image showing three different Frank partial DLs located at different depths in the thickness of the TEM sample. Their lateral size varies between 5 and $20 \mathrm{~nm}$, suggesting that the DL coarsening process supported by $\mathrm{Ge}$ self-interstitial diffusion did not end at the end of the thermal annealing. ${ }^{24-27}$ Fig. 1(b) presents an APT volume measured in the same sample in the cross-section mode ${ }^{36,37}$ (the surface of the volume corresponds to $\mathrm{Ge}(110)$ ). Red, blue, and green dots correspond to single $\mathrm{Ge}, \mathrm{Te}$, and $\mathrm{Ni}$ atoms, respectively. The Ni atoms come from a $100 \mathrm{~nm}$-thick Ni cap deposited at room temperature on the sample surface for 


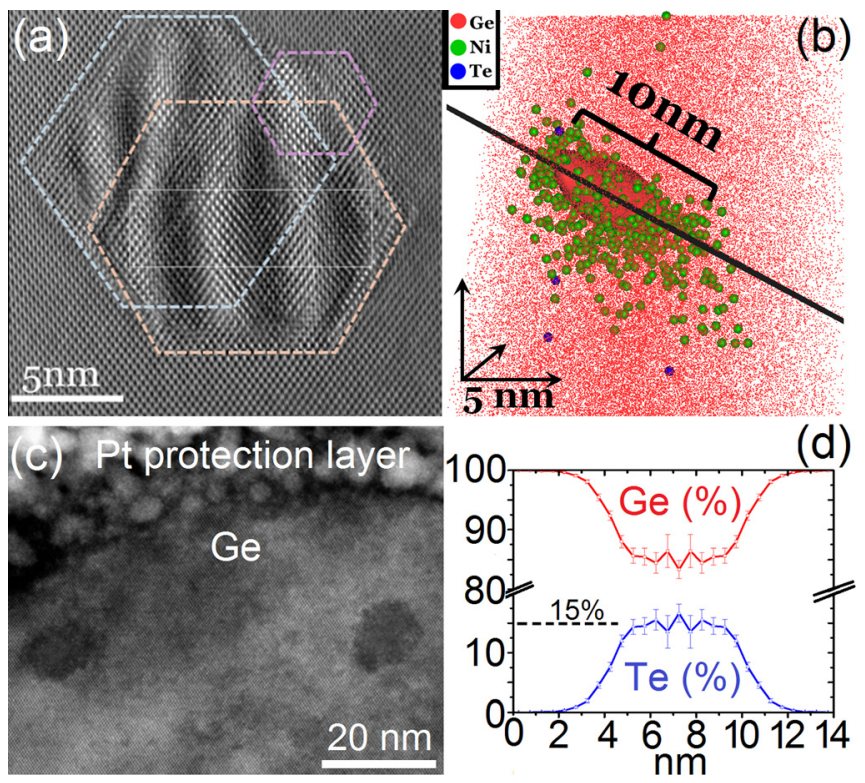

FIG. 1. TEM and APT analyses of the defects observed in the Ge(001) substrate after Te implantation and annealing at $650^{\circ} \mathrm{C}$ for $1 \mathrm{~h}$ : (a) HR-TEM cross-section image showing three partial dislocation loops viewed along the $\langle 110\rangle$ direction; (b) side view of an APT volume; the red, blue, and green dots correspond, respectively, to $\mathrm{Ge}$, Te, and Ni atoms, the red surface corresponds to an atomic iso-density of $7.5 \times 10^{22}$ at. $\mathrm{cm}^{-3}$; (c) HAADF-STEM cross-section image showing two partial dislocation loops; and (d) Ge and Te concentration profiles measured by APT through a Te cluster.

protection before APT sample preparation. ${ }^{36-38}$ A DL can be detected in this volume due to a local modification of the atomic density related to a local magnification effect caused by the DL during APT experiments. ${ }^{29,39-41}$ The red surface forming an elongated volume corresponds to an atomic isodensity of $7.5 \times 10^{22}$ at. $\mathrm{cm}^{-3}$, about two times greater than the atomic density in the rest of the APT volume $\left(4.0 \times 10^{22}\right.$ at. $\mathrm{cm}^{-3}$ ), which is consistent with the presence of a Frank partial DL bounding an extrinsic stacking fault (ESF). This atomic density increase in DL vicinity has the same origin as the density increase found in Ge grain boundary surrounding. ${ }^{42}$ The black line in Fig. 1(b) shows the orientation of the DL plane. It forms an angle of $\sim 38.5 \pm 5^{\circ}$ with the normal of the surface of the APT volume, in agreement with the angle $\left(34.3^{\circ}\right)$ between the $\langle 111\rangle$ and $\langle 110\rangle$ directions in the Ge lattice. Few Te atoms are detected in the APT volume but they are located far from the DL. Contrasting with previous measurements concerning classical dopants in $\mathrm{Si}$, Te atoms do not segregate on DLs. However, Ni atoms from the surface Ni cap are found to form a Cottrell atmosphere surrounding the DL, as observed in the case of Si DLs. ${ }^{29,43}$ Indeed, $\mathrm{Ni}$ atoms can diffuse at room temperature in $\mathrm{Ge}$, since they use the interstitial mechanism such as in $\mathrm{Si}^{12}$ The local $\mathrm{Ni}$ composition in the DL vicinity was found to be $\sim 5 \%$, which is smaller than the $\mathrm{Ni}$ composition found in $\mathrm{Si}$ DL vicinity $(\sim 10 \%)$, but of same magnitude. ${ }^{29,43}$ These results were confirmed by HAADF-STEM imaging: no Te atoms could be detected on the DLs. For example, Fig. 1(c) presents a HAADF-STEM image showing two DLs separated by about $50 \mathrm{~nm}$, exhibiting a hexagonal shape and a darker contrast compared to the surrounding Ge matrix. No Te atom was detected on the DL or in its immediate vicinity. Te atoms should give a brighter contrast in HAADF analyses, since they are significantly heavier than Ge atoms. The slight intensity decrease observed within the Frank partial DL is attributed here to the presence of the ESF and the resulting dechanneling of the electrons, but it must not be correlated with the local chemical content. Te-Ge clusters were also detected at similar depth as DLs. Their average lateral size is $\sim 5 \pm 2 \mathrm{~nm}$ and their average Te composition is $\sim 10 \pm 5 \%$ from APT analyses. Fig. 1(d) presents the Te and the Ge one-dimensional composition profiles measured by APT throughout one of these clusters exhibiting a lateral size of $\sim 6 \mathrm{~nm}$. The Te composition inside the cluster is homogeneous and about $15 \%$. These Te-Ge clusters do not correspond to a known compound from the Te-Ge phase diagram, since Te and Ge can only form the compound GeTe, corresponding to a Te composition of $50 \% .^{23}$ The melting temperature of $\mathrm{Te}\left(449.6^{\circ} \mathrm{C}\right)$ and $\mathrm{GeTe}\left(724^{\circ} \mathrm{C}\right)$ being significantly lower than that of $\mathrm{Ge}\left(938.3^{\circ} \mathrm{C}\right)$, the cluster evaporation field is expected to be lower than that of the Ge matrix, suggesting a local "focalization effect" in cluster vicinity in the APT volumes. ${ }^{40}$ Indeed, the average atomic density in the clusters $\left(6.7 \times 10^{22} \mathrm{~cm}^{-3}\right)$ was found to be about $49 \%$ higher than in the Ge matrix $\left(4.5 \times 10^{22} \mathrm{~cm}^{-3}\right)$. Thus, part of the Ge atoms found in the Te-Ge clusters is probably coming from the matrix surrounding the clusters. Assuming that (i) the clusters should possess the atomic density of the GeTe compound $\left(3.7 \times 10^{22} \mathrm{~cm}^{-3}\right)$, and (ii) the extra atomic density in the clusters is only resulting from additional Ge atoms from the matrix, the corrected average Te composition in the clusters is found to be $18 \%$ instead of $10 \%$. Consequently, the detected Te-Ge clusters probably correspond to nonstoichiometric clusters as proposed by non-classical nucleation theories. ${ }^{44}$ Since Te could form clusters during annealing, the diffusion kinetic of Te atoms is not the limiting factor preventing Te atoms from reaching the DLs, from segregating, and from precipitating on the DLs. In addition, the entire Te dose measured by APT in the clusters is $\sim 2.5 \times 10^{14}$ at. $\mathrm{cm}^{-2}$, which corresponds to $\sim 0.08$ times the implanted dose, meaning that a significant reservoir of $\mathrm{Te}$ atoms in solution in the sample was available to decorate the Te-free DLs observed in the sample.

In order to understand the unusual interactions between Te atoms and Ge Frank DLs, simulations were performed at the atomistic scale, the same scale as the HR-TEM and APT measurements. Both chemical and elastic interactions need to be taken into account for modelling precipitation and segregation, and the simulation cell should be large enough to contain an entire isolated Frank DL formed by an interstitial disc located in between two adjacent $\{111\}$ planes of the diamond structure shuffle set. In this case, KMC simulation on a rigid lattice appears as the best solution to simulate the experimental results. Because of calculation time restrictions, chemical interactions are usually modelled using atomic pair energies, and elastic interactions are taken into account using a continuum model. ${ }^{34}$ However, in order to get an elastic description of the system at the atomic scale, it was preferred to use a semi-empirical potential to determine the stress state of each atomic site. ${ }^{45,46}$ A hexagonal $5 \mathrm{~nm}$-wide atomic plane made of 183 atoms was inserted between two (111) atomic planes of the Ge diamond lattice $\left(8.69 \times 8.69 \times 8.69 \mathrm{~nm}^{3}\right.$ cell with periodic conditions in the three spatial directions), and fully 
relaxed by the Monte Carlo technique at $600^{\circ} \mathrm{C}$ using the $\mathrm{Ge}$ SW potential in order to model a DL. ${ }^{46}$ The SW potential was already used to simulate $\mathrm{Te}$ interatomic interactions. ${ }^{4-50}$ However, it was parametrized based on the Si parameters only for the diamond lattice, aiming to match the energy and lattice constant of a given compound such as CdTe in the zinc-blende structure, and a fictitious pure Te in the diamond structure. We propose a different set of parameters given in Table I, based on the Ge SW parameters from Yu et al. ${ }^{46,51}$ As the rigid lattice of the Ge matrix has a cubic symmetry, the SW Te-Te potential was parametrized to stabilise pure Te in the fcc structure, instead of the real hexagonal structure, with a lattice parameter $a$ equal to the two identical lattice parameters $a$ and $b$ $(=0.44572 \mathrm{~nm})$ of the hexagonal structure, and to match the Te cohesive energy $E_{c o h}=-2.23 \mathrm{eV} \mathrm{at}^{-1}$ and the Te bulk modulus $B=65 \mathrm{GPa}$. Te and $\mathrm{Ge}$ can only form a single compound GeTe with the rock-salt structure at $T>430{ }^{\circ} \mathrm{C} .{ }^{23}$ Thus, the SW Te-Ge potential was parametrized to stabilise this structure with $a_{\mathrm{GeTe}}=0.585 \mathrm{~nm}, \quad E_{c o h}{ }^{\mathrm{GeTe}}=-3.45 \mathrm{eV} \quad$ at. $^{-1}$, and $B_{\mathrm{GeTe}}=51 \mathrm{GPa}$ from $a b$ initio calculations at $T=0 \mathrm{~K} .{ }^{52}$ The relaxation was performed by $\mathrm{MC}$ at $10 \mathrm{~K}$. The parameters from Table I lead to $a_{\mathrm{Te}}=0.44572 \mathrm{~nm}, E_{c o h}{ }^{\mathrm{Te}}=-2.23 \mathrm{eV}$ at. $^{-1}, \quad B_{\mathrm{Te}}=61.6 \mathrm{GPa} ; \quad$ and $a_{\mathrm{GeTe}}=0.585 \mathrm{~nm}, \quad E_{c o h}{ }_{\mathrm{GeTe}}$ $=-3.45 \mathrm{eV}$ at. $^{-1}$, and $B_{\mathrm{GeTe}}=49.8 \mathrm{GPa}$. The energy $E_{0}$ of each substitutional site $(\mathrm{S})$ and tetrahedral interstitial (TI) site of the relaxed cell containing the DL was calculated using the SW potential, by placing an isolated Te atom on each considered site. Thus, Te atoms were randomly inserted sequentially on the Ge S sites and allowed to move to first neighbouring $\mathrm{S}$ and TI sites following the Metropolis algorithm ${ }^{45,46,53}$ during $\mathrm{KMC}$ simulations at $600^{\circ} \mathrm{C}$. Each Te atom in the simulation cell performed $10^{6}$ migration jumps before an additional $\mathrm{Te}$ atom was inserted. Figs. 2(a) and 2(b) present the simulation results obtained in the case of a migration energy $E_{m}=\Delta E_{0}=E_{0 f}-E_{0 i}$, with $E_{0 i}$ the Te atom energy on the initial site before migration and $E_{0 f}$ the Te atom energy on the final site after migration. $400 \mathrm{Te}$ atoms were inserted in the simulation cell, which corresponds to a Te concentration of $\sim 5.3 \times 10^{20} \mathrm{~cm}^{-3}$. The simulation time is equivalent to $4.57 \times 10^{7} \mathrm{~s}(\sim 529$ days $)$, considering the Te experimental diffusion coefficient in Ge $D=5.6 \times \exp \left(-2.43 \mathrm{eV} / k_{B} T\right) \mathrm{cm}^{2} \mathrm{~s}^{-1}$ (giving a diffusion length of $330 \mathrm{~nm}$ for annealing at $650{ }^{\circ} \mathrm{C}$ for $1 \mathrm{~h}$ ). ${ }^{54}$ All the Te atoms occupy $\mathrm{S}$ sites (Fig. 2(a)). The majority of Te atoms are located several atomic planes away from the Frank DL, leaving a Te-free region surrounding the DL. Only 13 atoms are located on the DL (Fig. 2(a)). Few atoms are sited on the DL edges, but the majority of atoms are sited on the dislocation plane. No Te cluster was formed. It is interesting to note that as the Te atoms have the same number of

TABLE I. Parameters of the Stillinger-Weber potential used in this work.

\begin{tabular}{lccc}
\hline \hline & Ge-Ge & Te-Te & Ge-Te \\
\hline$\varepsilon$ & 1.925 & 0.3171 & 6.33 \\
$\sigma$ & 2.181 & 2.64 & 2.59 \\
$A$ & 7.049556277 & 11.0 & 11.0 \\
$\delta$ & 1.0 & 1.0 & 2.0353 \\
$\lambda$ & 19.5 & 5.5 & 5.5 \\
$\cos \theta_{t}$ & $-1 / 3$ & 0.0 & 0.0 \\
\hline \hline
\end{tabular}
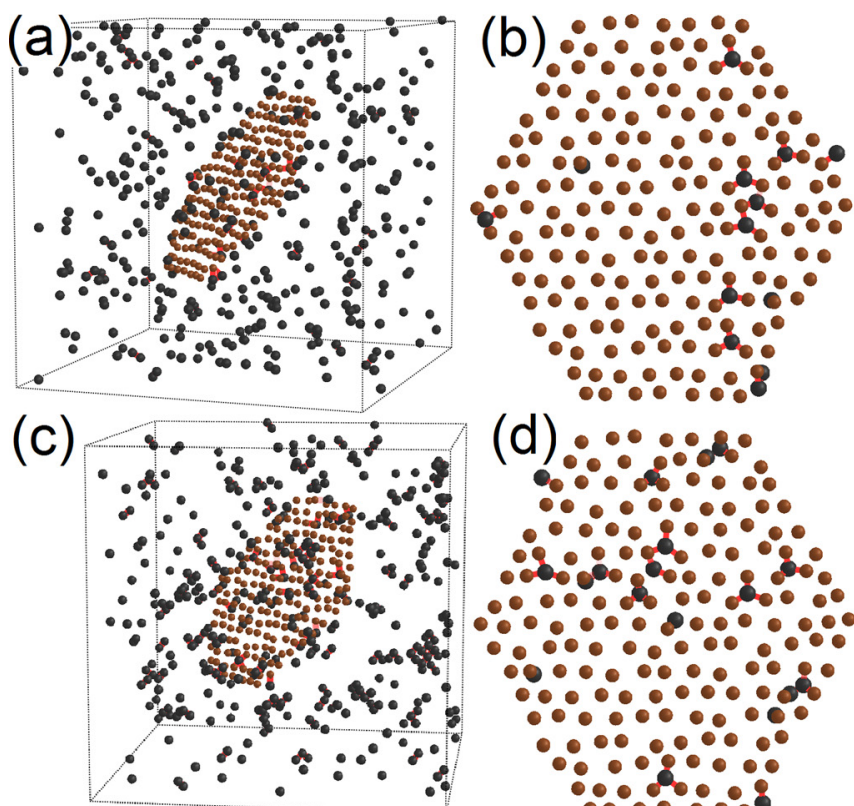

(e)

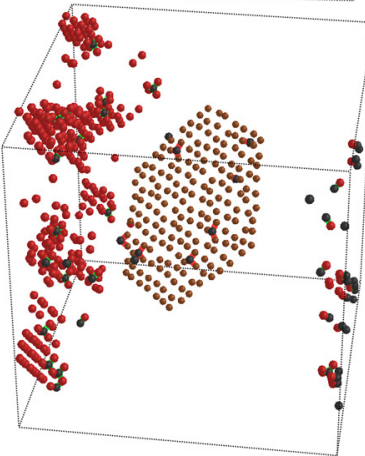

(d)

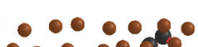

$000 \%$

- 100

$-0.0$
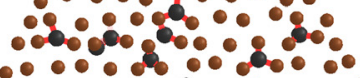

$\therefore$ - 00.00

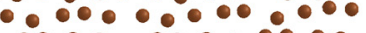

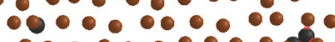

$\because 000$

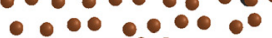

$\because \div 00$ $\because \div 08$

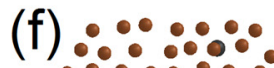

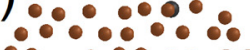

$\therefore 0$

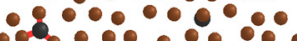
-

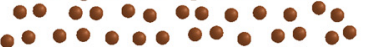
$\therefore \circ \div 0$

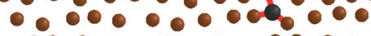

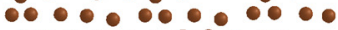
$\because \therefore \circ$

00

00000 $\because \because 0$

FIG. 2. KMC simulation results showing the entire simulation cell ((a), (c), and (e)) as well as the atomic distribution within the partial DL, in the plane of the extrinsic stacking fault ((b), (d), and (f)): (a) and (b) SW potential; (c) and (d) SW potential and Te-Te pair interactions; and (e) and (f) SW potential, Te-Te pair interactions, and Coulombic interactions. Brown, black, and red dots correspond to Ge atoms in the dislocation plane, Te atoms on the substitutional lattice, and Te atoms on the interstitial lattice, respectively. In all the presented cases, the number of Te atoms introduced in the cell is 400, and the simulation time corresponds to $4.57 \times 10^{7} \mathrm{~s}$.

Ge first neighbours on S sites and TI sites in the same tetrahedral structure, $\Delta E_{0}$ can be considered to be mainly related to the difference of stress states between the two considered sites on a radius up to the first neighbour distance. ${ }^{45,46}$ Indeed, the denuded region was found to match the pressure variations on the atomic sites, namely, the atomic sites exhibiting the highest pressure were found to be free of Te atoms. In order to simulate the possible formation of Te-Ge clusters on the two rigid lattices (substitutional and interstitial), the SW potential was used to calculate the average energy $\varepsilon_{G e T e}$ of the first neighbour Te-Ge bond in a relaxed 13-atom GeTe cluster nucleating in fcc Ge (the Te fcc sub-lattice of the GeTe rock-salt structure was filled atom by atom while the Ge fcc sub-lattice was fully occupied). As no Ge atom were allowed to move, and the number of first Ge neighbour was the same on $\mathrm{S}$ and TI sites, cluster formation can only be modelled in our geometry (rigid lattice) by the formation of a pure Te cluster. Thus, the first neighbour Te-Te bond energy was set to be the same as $\varepsilon_{G e T e}=-0.78 \mathrm{eV}$ at. $^{-1}$, aiming to scale the clustering energy to the elastic energy $E_{0}$ calculated with the same potential. 
Figs. 2(c) and 2(d) present the results obtained considering $E_{m}=\Delta E_{0}+\Delta E_{b}$, with $\Delta E_{b}$ the energy difference based on first neighbour pair energy. All the Te atoms still occupy $S$ sites. The Te-free region surrounding the DL is still present, and several Te atoms are located on the DL. However, small Te clusters were formed away from the DL in agreement with the experimental observations. Substitutional Te atoms are expected to be activated, and thus, to carry two positive elementary charges. In addition, vacancies $(V)$ were shown to carry two negative elementary charges in $n$-type $\mathrm{Ge},{ }^{55}$ and to interact with dopants forming mobile dopant $-V$ complexes. ${ }^{56-63}$ Consequently, one could expect the formation of uncharged mobile $\mathrm{Te}^{0}$ pairs in our case. In addition, the $\mathrm{Te}$ atoms forming GeTe clusters are also expected to be neutral. Thus, KMC simulations were also performed considering coulombic interactions between $\mathrm{Te}^{2+}$ ions located on $\mathrm{S}$ sites (activated $n$-type dopants), and $\mathrm{Te}^{0}$ atoms located on TI sites to model mobile species allowed to cluster on the interstitial sublattice. Furthermore, since no Te atoms were detected experimentally on the DLs, the Te atoms located on the DL were assumed to carry a single positive charge in order to have repulsive interactions between Te atoms on the DL, as well as between substitutional Te atoms and Te atoms located on the DL. Figs. 2(e) and 2(f) present the results obtained considering $E_{m}=\Delta E_{0}+\Delta E_{b}+\Delta E_{c}$, with $\Delta E_{c}$ the coulombic energy difference. In this case, the Te atom majority occupies TI sites and formed larger clusters located away from the DL. In addition, the number of Te atoms located on the DL decreased by $\sim 50 \%$ (only $7 \mathrm{Te}$ atoms instead of 13 considering only the elastic effect). These results are in better agreement with the experimental observations. It is interesting to note that without the DL in the simulation cell, the repulsive coulombic interactions between the $\mathrm{Te}^{2+}$ ions located on $\mathrm{S}$ sites have a strong impact on the Te distribution. Indeed, when the $\mathrm{Te}^{2+}$ ions concentration reaches $5.5 \times 10^{19} \mathrm{~cm}^{-3}$ in the cell, Te atoms start to pass from S sites to TI sites, meaning that the repulsive coulombic energy rose beyond the formation energy of uncharged $\mathrm{TI} \mathrm{Te}$ atoms. The maximum concentration of activated $\mathrm{Te}$ atoms that was achieved was about $8.5 \times 10^{19} \mathrm{~cm}^{-3}$. All the Te atoms occupy TI sites beyond this concentration.

In conclusion, high resolution TEM and APT analyses were used to study Te atom interactions with Ge Frank DLs in the case of Ge $n$-type doping. Atomic scale observations showed that in contrast with usual Si dopants such as B, As, and $\mathrm{P}, \mathrm{Te}$ atoms do not segregate on Ge DLs, and in contrast with common expectations, Te does not precipitate on the DLs but between the DLs, preferring homogeneous nucleation instead of heterogeneous nucleation that is generally energetically favoured. Atomic scale KMC simulations show that Te atoms are repulsed from Ge DLs due to elastic interactions. Te atoms on S and TI sites surrounding the Ge DLs (up to 4-5 atomic planes) are subjected to a strong compressive stress, leading to a Te-free region around the DLs even at high temperatures $\left(600{ }^{\circ} \mathrm{C}\right.$ in the simulations). However, few Te atoms were found to attach to the extrinsic stacking fault bounded by the Frank DL, which was not evidenced by the experimental observations. The scenario the closest to the experiments, leading to the nucleation of Te clusters far from the DLs with a reduced number of Te atoms attached to the dislocation plane, also considers coulombic interactions in the case of activated $\mathrm{Te}^{2+}$ ions, $\mathrm{Te}^{0}$ atoms as mobile species (in agreement with $\mathrm{Te} V^{0}$ mobile pairs), and $\mathrm{Te}^{1+}$ ions attached to the dislocation plane.

This work was supported by the French National Agency for Research (ANR) through the program "Science de l’ingénierie" (Project DoGeTec, No. ANR-12-JS09-0015-1).

${ }^{1}$ J.-H. Park, D. Kuzum, M. Tada, and K. C. Saraswat, Appl. Phys. Lett. 93, 193507 (2008).

${ }^{2}$ A. Toriumi, T. Tabata, C. H. Lee, T. Nishimura, K. Kita, and K. Nagashio, Microelectron. Eng. 86, 1571 (2009).

${ }^{3}$ R. Pillarisetty, Nature 479, 324 (2011).

${ }^{4}$ S. Takagi, R. Zhang, and M. Takenaka, Microelectron. Eng. 109, 389 (2013).

${ }^{5}$ G. Lucovsky, J. W. Kim, and D. Nordlund, Microelectron. Eng. 109, 370 (2013).

${ }^{6}$ J. Robertson and R. M. Wallace, Mater. Sci. Eng. R 88, 1 (2015).

${ }^{7}$ E. Dib, M. Bescond, N. Cavassilas, F. Michelini, L. Raymond, and M. Lannoo, J. Appl. Phys. 114, 083705 (2013).

${ }^{8}$ C. Claeys, J. Mitard, G. Eneman, M. Meuris, and E. Simoen, Thin Solid Films 518, 2301 (2010).

${ }^{9}$ L. Ye, M. Zhang, Z. Xue, J. Yang, X. Wanga, and Z. Dia, Appl. Surf. Sci. 356, 1052 (2015).

${ }^{10}$ F. Ji, J. P. Xu, L. Liu, W. M. Tang, and P. T. Lai, Microelectron. Reliab. 57, 24 (2016).

${ }^{11}$ E. Simoen, A. Satta, A. D’Amore, T. Janssens, T. Clarysse, K. Martens, B. De Jaeger, A. Benedetti, I. Hoflijk, B. Brijs, M. Meuris, and W. Vandervorst, Mater. Sci. Semicond. Process. 9, 634 (2006).

${ }^{12}$ H. Bracht and S. Brotzmann, Mater. Sci. Semicond. Process. 9, 471 (2006).

${ }^{13}$ J. Kim, S. W. Bedell, S. L. Maurer, R. Loesing, and D. K. Sadana, Electrochem. Solid-State Lett. 13, H12 (2010).

${ }^{14}$ M. Oehme, J. Werner, and E. Kasper, J. Cryst. Growth 310, 4531 (2008).

${ }^{15}$ G. Impellizzeri, S. Mirabella, A. Irrera, M. G. Grimaldi, and E. Napolitani, J. Appl. Phys. 106, 013518 (2009).

${ }^{16}$ G. Impellizzeri, S. Mirabella, E. Bruno, A. M. Piro, and M. G. Grimaldi, J. Appl. Phys. 105, 063533 (2009).

${ }^{17}$ M. El Kurdi, T. Kociniewski, T.-P. Ngo, J. Boulmer, D. Débarre, P. Boucaud, J. F. Damlencourt, O. Kermarrec, and D. Bensahel, Appl. Phys. Lett. 94, 191107 (2009).

${ }^{18}$ D. Klinger, J. Auleytner, A. Barcz, and D. Żymierska, J. Alloys Compd. 362, 265 (2004).

${ }^{19}$ C. Wündisch, M. Posselt, B. Schmidt, V. Heera, T. Schumann, A. Mücklich, R. Grötzschel, W. Skorupa, T. Clarysse, E. Simoen, and H. Hortenbach, Appl. Phys. Lett. 95, 252107 (2009).

${ }^{20}$ Y. Yamamoto, K. Köpke, R. Kurps, J. Murota, and B. Tillack, Thin Solid Films 518, S44 (2010).

${ }^{21}$ R. Milazzo, G. Impellizzeri, D. Piccinotti, A. La Magna, G. Fortunato, D. De Salvador, A. Carnera, A. Portavoce, D. Mangelinck, V. Privitera, and E. Napolitani, J. Appl. Phys. 119, 045702 (2016).

${ }^{22}$ F. Cristiano, M. Shayesteh, R. Duffy, K. Huet, F. Mazzamuto, Y. Qiu, M. Quillec, H. H. Henrichsen, P. F. Nielsen, D. H. Petersen, A. La Magna, G. Caruso, and S. Boninelli, Mater. Sci. Semicond. Process. 42, 188 (2016).

${ }^{23}$ A. Gokhale and G. J. Abbaschian, Binary Alloy Phase Diagrams, 2nd ed. (ASM International, 1990), Vol. 2, p. 1964.

${ }^{24}$ A. Claverie, B. Colombeau, G. B. Assayag, C. Bonafos, F. Cristiano, M. Omri, and B. de Mauduit, Mater. Sci. Semicond. Process. 3, 269 (2000).

${ }^{25}$ F. Cristiano, J. Grisolia, B. Colombeau, M. Omri, B. de Mauduit, A. Claverie, L. F. Giles, and N. E. B. Cowern, J. Appl. Phys. 87, 8420 (2000).

${ }^{26}$ F. Cristiano, N. Cherkashin, X. Hebras, P. Calvo, Y. Lamrani, E. Scheid, B. de Mauduit, B. Colombeau, W. Lerch, S. Paul, and A. Claverie, "Ion beam induced defects in crystalline silicon," Nucl. Instrum. Methods Phys. Res., Sect. B 216, 46 (2004)

${ }^{27}$ A. Claverie, S. Koffel, N. Cherkashin, G. Benassayag, and P. Scheiblin, Thin Solid Films 518, 2307 (2010).

${ }^{28}$ E. M. Bazizi, A. Pakfar, P. F. Fazzini, F. Cristiano, C. Tavernier, A. Claverie, N. Zographos, C. Zechner, and E. Scheid, Thin Solid Films 518, 2427 (2010).

${ }^{29}$ K. Hoummada, D. Mangelinck, B. Gault, and M. Cabié, Scr. Mater. 64, 378 (2011).

${ }^{30}$ K. Thompson, P. L. Flaitz, P. Ronsheim, D. J. Larson, and T. F. Kelly, Science 317, 1370 (2007). 
${ }^{31}$ S. Duguay, A. Colin, D. Mathiot, P. Morin, and D. Blavette, J. Appl. Phys. 108, 034911 (2010).

${ }^{32}$ S. Duguay, T. Philippe, F. Cristiano, and D. Blavette, Appl. Phys. Lett. 97, 242104 (2010).

${ }^{33}$ S. Y. Hu and L. Q. Chen, Acta Mater. 49, 463 (2001).

${ }^{34}$ C. Hin, Y. Bréchet, P. Maugis, and F. Soisson, Acta Mater. 56, 5535 (2008).

${ }^{35}$ H. Li, S. Xia, B. Zhou, and W. Liu, Mater. Charact. 66, 68 (2012).

${ }^{36}$ D. Mangelinck, K. Hoummada, A. Portavoce, C. Perrin, R. Daineche, M. Descoins, D. J. Larson, and P. H. Clifton, Scr. Mater. 62, 568 (2010).

${ }^{37}$ D. J. Larson, T. J. Prosa, R. M. Ulfig, B. P. Geiser, and T. F. Kelly, Local Electrode Atom Probe Tomography (Springer, New York, 2013).

${ }^{38}$ A. Portavoce, K. Hoummada, A. Ronda, D. Mangelinck, and I. Berbezier, Beilstein J. Nanotechnol. 5, 2374 (2014).

${ }^{39}$ M. K. Miller, J. Phys., Colloq. 48, C6-565-C6-570 (1987).

${ }^{40}$ F. Vurpillot, A. Bostel, and D. Blavette, Appl. Phys. Lett. 76, 3127 (2000).

${ }^{41}$ G. Sha and A. Cerezo, Ultramicroscopy 102, 151 (2005).

${ }^{42}$ A. Portavoce, O. Abbes, A. Spiesser, C. Girardeaux, L. Michez, and V. Le Thanh, Scr. Mater. 100, 70 (2015).

${ }^{43}$ K. Hoummada, G. Tellouche, I. Blum, A. Portavoce, M. Descoins, and D. Mangelinck, Microelectron. Eng. 107, 184 (2013).

${ }^{44}$ T. Philippe, D. Blavette, and P. W. Voorhees, J. Chem. Phys. 141, 124306 (2014).

${ }^{45}$ A. Portavoce and G. Tréglia, Acta Mater. 65, 1 (2014).

${ }^{46}$ A. Portavoce, J. P. Toinin, K. Hoummada, L. Raymond, and G. Tréglia, Comput. Mater. Sci. 114, 23 (2016).

${ }^{47}$ Z. Q. Wang, D. Stroud, and A. J. Markworth, Phys. Rev. B 40, 3129 (1989).
${ }^{48}$ C. H. Grein, J. P. Faurie, V. Bousquet, E. Tourni, R. Benedek, and T. de la Rubia, J. Cryst. Growth 178, 258 (1997).

${ }^{49}$ K. Scheerschmidt, D. Conrad, H. Kirmse, R. Schneider, and W. Neumann, Ultramicroscopy 81, 289 (2000).

${ }^{50}$ Z. Zhang, X. Zhang, X. Guo, F. Ye, and Y. Huo, Scr. Mater. 69, 457 (2013).

${ }^{51}$ W. Yu, Z. Q. Wang, and D. Stroud, Phys. Rev. B 54, 13946 (1996).

${ }^{52}$ K. M. Rabe and J. D. Joannopoulos, Phys. Rev. B 36, 3319 (1987).

${ }^{53}$ N. Metropolis, A. W. Metropolis, M. N. Rosenbluth, A. H. Teller, and E. Teller, J. Chem. Phys. 21, 1087 (1953).

${ }^{54}$ V. D. Ignatkov and V. E. Kosenko, Sov. Phys. - Solid State 4, 1193 (1962).

${ }^{55}$ T. Südkamp, H. Bracht, G. Impellizzeri, J. L. Hansen, A. N. Larsen, and E. E. Haller, Appl. Phys. Lett. 102, 242103 (2013).

${ }^{56}$ V. P. Markevich, I. D. Hawkins, A. R. Peaker, K. V. Emtsev, V. V. Emtsev, V. V. Litvinov, L. I. Murin, and L. Dobaczewski, Phys. Rev. B 70, 235213 (2004).

${ }^{57}$ A. Chroneos, R. W. Grimes, and C. Tsamis, Mater. Sci. Semicond. Process. 9, 536 (2006).

${ }^{58}$ J. Coutinho, C. Janke, A. Carvalho, V. J. B. Torres, S. Öberg, R. Jones, and P. R. Briddon, Phys. B 401-402, 179 (2007).

${ }^{59}$ S. Brotzmann, H. Bracht, E. Simoen, E. E. Haller, J. S. Christensen, and P. Werner, Phys. Rev. B 77, 235207 (2008).

${ }^{60}$ A. Chroneos, H. Bracht, R. W. Grimes, and B. P. Uberuaga, Appl. Phys. Lett. 92, 172103 (2008).

${ }^{61}$ A. Chroneos, J. Appl. Phys. 107, 076102 (2010).

${ }^{62}$ H. Tahini, A. Chroneos, R. W. Grimes, U. Schwingenschlögl, and H. Bracht, Appl. Phys. Lett. 99, 072112 (2011).

${ }^{63}$ A. Chroneos and H. Bracht, Appl. Phys. Rev. 1, 011301 (2014). 